\title{
A Study Of Undergraduate Students' Alternative Conceptions Of Earth's Interior Using Drawing Tasks
}

\author{
Meredith L. McAllister, Butler University, USA
}

\begin{abstract}
Learning fundamental geoscience topics such as plate tectonics, earthquakes, and volcanoes requires students to develop a deep understanding of the conceptual models geologists use when describing the structure and dynamics of Earth's interior. Despite the importance of these mental models underlying much of the undergraduate geoscience curriculum, surprisingly little research related to this complex idea exists in the discipline-based science education research literature. To better understand non-science-majoring undergraduates' conceptual models of Earth's interior, student-generated drawings and interviews were used to probe student understanding of the Earth. Ninety-two semi-structured interviews were conducted with non-science-major college students at the beginning of an entry-level geology course at a large Midwestern university. Students were asked to draw a picture of Earth's interior and provide think-aloud explanations of their drawings. The results reveal that students hold a wide range of alternative conceptions about Earth, with only a small fraction having scientifically accurate ideas. Students' understandings ranged from conceptualizing Earth's interior as consisting of horizontal layers of rock and dirt, to more sophisticated views with Earth's interior being composed of concentric layers with unique physical and chemical characteristics. Processes occurring within Earth, such as "convection," were rarely mentioned or explained. These results provide a first-steps basis from which to further explore college students' thinking and contribute to the growing body of knowledge on earth science teaching and geoscience education research.
\end{abstract}

Keywords: Geology Education; Undergraduate Geoscience; Earth's Interior

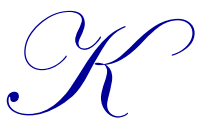

nowing and understanding science enables students to make better decisions about themselves and enhances their interactions with the natural world. As part of achieving scientific literacy, informed students begin to see valuable connections between basic science and real-world situations, such as the occurrence of earthquakes and volcanoes, while acquiring the necessary skills to become lifelong learners (Gill, 1999). Although most US students will have taken an Earth science course at some point, often between the ages of 12 and 14 years, dynamic geological processes occurring within Earth are challenging to learn because they often cannot be observed directly. The completeness of students' understanding of Earth's interior ultimately impacts their learning of related concepts, such as plate movement and the causes of earthquakes and volcanoes, because an accurate conception of Earth's interior seems to be a prerequisite for related concepts.

Geoscience students taking undergraduate courses are often asked to picture and organize parts of Earth that cannot be touched or examined firsthand (Hall-Wallace, 2002). Students' inability to directly view Earth's interior makes this topic conceptually complex. Earth science educators have used various instructional strategies to help students construct scientifically appropriate mental models of Earth's interior. For instance, Hall-Wallace (2002) noted that analogies, simulations, and animations have been used with measureable success when teaching this topic. Nevertheless, students often enter undergraduate introductory geology survey courses, often refereed to as GEOL 101, with misconceptions or alternative conceptions of how Earth works and may finish their coursework with these same inaccurate ideas. More worrisome, common analogies used within the classroom and in the media 
may further encourage the development of alternative conceptions (e.g., the inaccurate notion that Earth's mantle is entirely composed of molten magma).

Authors have long argued that, as a result of a lack of effective representations and illustrations within the K-12 curriculum and the abstract nature of geoscience textbooks, students' Earth science conceptions are often inconsistent with scientific thinking and can be viewed as pseudo-scientific or nonscientific (viz., Stead \& Osborne, 1980; Solomon, 1987). These conceptions have been referred to using various terminology such as "naive beliefs," "preconceptions," "alternative conceptions," and "misconceptions" (Ault, 1984; Bezzi \& Happs, 1994). Many researchers use the term "misconception" in studies where students have been exposed to some formal mental model of a science concept but have assimilated the model incorrectly (Clement, Brown, \& Zietsman, 1989). Alternatively, the term "alternative conception," is more often used to describe a students' incoming concept conceived prior to formal instruction that is inconsistent with the current scientific understanding (Abimbola, 1988; Stead \& Osborne, 1980). The term Alternative conception is preferred in the present work because it confers intellectual respect to learners who hold intuitive ideas (Wandersee, James, Mintzes, \& Novak, 1994). Although a considerable amount of alternative-conceptions research has been carried out in scientific disciplines such as physics and chemistry (Brown, 1989; Clement, Brown, \& Zietsman, 1989; Gabel, 1989), the number of studies that have been conducted in the geoscience domains are limited.

Students' mental models or conceptions of phenomena have been studied in a variety of ways, including student interviews, student-generated maps, multiple-choice and open-response assessments, as well as studentgenerated drawings (Ault, 1984; Bar, 1989; Beilfuss (McAllister), 2004; Capps, et al., 2013; Chang \& Barufaldi, 1999; Dove, 1998; Marques \& Thompson, 1997a; Muthukrishna et al., 1993; Schoon, 1989). Drawings have been used to explore students' conceptual knowledge of the Earth's interior (Bar, 1989; Beilfuss (McAllister), 2004; Capps, 2013; Lillo, 1994). This drawing-based approach because alternative-conceptions assessment methods emphasize verbal rather than visual skills, and drawing tasks in combination with an interview provide an opportunity to utilize two methods of determining students' understanding.

Only a few studies have touched upon student's conceptions of Earth's interior (Beilfuss (McAllister), 2004; Capps et al., 2013; Dal, 2007; DeLaughter, et al., 1998; Gobert \& Clement, 1998; Lillo, 1994; Nottis \& Ketter, 1999; Sharp et al., 1995), three of which touch upon the ideas of college students (Capps, et al., 2013; DeLaughter, et al., 1998; King, 2000). The 1998 study conducted by DeLaughter, Stein, Stein, and Bain assessed 149 undergraduates from an introductory geology course. These students were asked to complete an "Earth science literacy" test. In addition to answering questions on other geoscience concepts, such as earthquakes and geologic time, students taking the Earth science literacy test were required to sketch a diagram of Earth's interior. Most students $(66 \%)$ sketched Earth as a concentrically layered planet, while some students (12\%) perceived Earth's interior as consisting of flat layers within a circle. After examining the results of the test, the authors recommended that key areas in Earth science might benefit from a renewed focus on conceptual change by geoscience instructors.

A similar study, conducted by King (2000), examined ideas held by 61 inservice teachers. Participants were asked to describe the physical state of each of the sections shown in a diagram of Earth's interior on a paper and pencil test. It is interesting that over half of the teachers did not realize that the outer core is liquid and a third did not know that the inner core is a solid. Both of these studies are limited to presenting simple generalized results from a paper and pencil test, rather than using analytical methods or multiple data collection methods, such as studentgenerated drawings coinciding with an interview.

Other studies in the literature focused on assessing younger children's conceptions of Earth's interior. For instance, Lillo (1994) studied Spanish primary students' conceptions of Earth's interior, and uncovered numerous alternative conceptions relating to the structure of the interior as well as to the cultural influences on children's ideas. For example, it was common for these children, aged 10-15, to believe that the center of Earth was molten and acted as the source for volcanic magma. Exaggerated thicknesses of Earth's concentric layers dominated students' drawings. It was also common for the older children to incorrectly position the spherical layers, usually by placing the asthenosphere above the mantle and not within the mantle. 
Similarly, while not specifically observing students' conceptions of Earth's interior, Gobert and Clement (1998) used student-generated diagrams to study students' construction of a model for plate tectonic processes. It was their belief that students aged 10-11 would gain a deeper understanding of plate tectonics if they produced a series of increasingly complex diagrams, or mental representations, of the plate tectonics process and then used the diagrams to infer the processes of volcanism and earthquakes. The authors noted, "This is a difficult topic to learn both because of the hidden explanatory mechanisms which are outside our direct experience, and because it involves several different types of knowledge including spatial, causal, and dynamic knowledge" (p. 938). In that particular study, students were asked to construct a spatial model of the layers within Earth, and then instructed to construct increasingly more complex diagrams in terms of the causal and dynamic information that is required to complete their understanding of plate tectonics. The results showed that the group of students who developed diagrams outperformed another group of students who only summarized their understanding of the text on plate tectonics. This was thought to have occurred because "providing summaries did not support the development of a dynamic mental model from which spatial information could be easily read, or from which further inferences about the causal and dynamic processes could be made" (p. 965). Clearly, visual learning can be powerful, and it appears to be very important for certain geoscience concepts with spatial characteristics.

Sharp and colleagues (1995) asked 9-10-year old children in the United Kingdom,"What is inside Earth?" Responses included objects such as bricks, skeletons, and pipes. After the researchers modified the question, most of the students in the study described the interior of Earth as solid, uniform, dark, and either warmer or colder than the surface. Dal (2007), using a sample of 120 Turkish students aged 13-14, observed alternative conceptions concerning ideas about the structure and process of crystals, volcanoes, and rocks. In most cases, students thought Earth to be composed of three layers: the crust, the core, and an in-between zone; Earth was filled with either water or magma; and the core served as the source of magma.

The 2013 study by Capps, McAllister, and Boone documented Honduran students' conceptions of Earth's interior. This qualitative study used participant-generated drawings and interviews to assess students' conceptions of Earth's interior. Results suggest that Honduran students, aged 9-14, held varying levels of understanding regarding this science concept. Many exhibited alternative conceptions of Earth's interior, including that it contained nonconcentric layers; physical objects, such as houses; and mythical creatures.

In summary, aspects of teaching and learning in many aspects of geoscience education historically include the use of concrete images. These include drawings in the dictionary, photographs in textbooks, computer animations, or the use of plastic models. "Often these images are not realistic; a map is an abstraction, as are charts and diagrams" (Cornett, 2002, p. 405), making learning effectively from these images challenging for the student. This motivates researchers to explore students' mental models and alternative conceptions using student-generated drawings. Drawings have been used elsewhere to successfully probe students' mental models of more abstract scientific concepts, such as the water cycle, groundwater, rivers, and mountains (Bar, 1989; Dove, 1999; Lillo, 1994; Samarapungavan, Vosniadou, \& Brewer, 1992), and is judged to be appropriate in the present case.

In response to the limited scope of the literature described above, college students' pre-college course knowledge of the interior of Earth was systematically examined using drawing tasks. The research question driving this study was:

What conceptions of Earth's interior exist among entry-level, undergraduate geoscience students?

\section{METHOD}

This descriptive study adopted a single-group, single-measure, phenomenological design. Data were collected from students at the beginning of an introductory undergraduate Earth science class, in order to better investigate and understand the geological conceptual knowledge held by such students. Within a phenomenological study it is essential that all participants have experienced the phenomena under study, and so a criterion sampling procedure was conducted (Creswell, 1998; Palmer, 1999), with the criterion being that each student had had some prior exposure to the concept of Earth's interior at some point in their experiences. While it was assumed that each undergraduate who volunteered to participate in the study would have been exposed to the concept of Earth's 
interior, it was thought that sampling students from an introductory geology class would be appropriate in ensuring exposure to the phenomena, albeit indirectly.

\section{Participants}

Interviewees were recruited during a class session of students enrolled in an entry-level geoscience course; students were motivated to participate through an extra credit offering by the instructor. One hundred and eightynine interviews, covering a range of topics including Earth's interior, were conducted. Only 92 students were asked specific questions regarding their understanding of Earth's interior. Interviewees ranged in age from 18-30, and the majority of the students were freshman and sophomore in class standing. Interviewees were $70 \%$ female and $92 \%$ Caucasian, with the majority (60\%) anticipating a major in elementary education. Demographic data collected within the study included prior undergraduate coursework, prior high school Earth science coursework, and parents' level of educational attainment. Table 1 provides an abridged summary of participants' self-reported gender, ethnicity, age, and major.

Table 1: Participant Demographics

\begin{tabular}{lcc}
\hline & Demographic & Percent of Participants (N=91) \\
\hline Gender & \\
\hline Female & $70 \%(\mathrm{n}=64)$ \\
Male & $30 \%(\mathrm{n}=27)$ \\
\hline Age (years) & $41 \%(\mathrm{n}=37)$ \\
\hline $18-19$ & $56 \%(\mathrm{n}=51)$ \\
$20-25$ & $3 \%(\mathrm{n}=3)$ \\
$26-30$ & \\
\hline Ethnicity & $91 \%(\mathrm{n}=83)$ \\
\hline Caucasian & $9 \%(\mathrm{n}=8)$ \\
Other & $60 \%(\mathrm{n}=55)$ \\
\hline Education majors &
\end{tabular}

Interviewees were enrolled in a course, "Earth - Our Habitable Planet," which presented a comprehensive view of the materials, processes, and history of Earth and Earth's four primary interacting systems - the atmosphere (air), hydrosphere (water), biosphere (organisms), and geosphere (rock). The textbook used for the course, "Our Blue Planet" (Skinner, Botkin, \& Porter, 1995), provides a brief overview of the concept of Earth's interior. The sample of students was selected over three semesters, with different instructors teaching the course at different times. Each instructor provided the students with different levels of exposure to the concept of Earth's interior. The sample of students for this study (92) was taken from the entire sample of 189 interviews, with the majority (57) recruited from a single professor's course.

\section{Procedure}

Each participant was interviewed on a single occasion. This limitation was the result of studying a large number of students. The interviews typically lasted 50-60 minutes, with 15-20 minutes spent on the topic of Earth's interior. All interviews were audiotaped and transcribed. Each interviewee created a drawing of Earth's interior. If the student appeared uncomfortable with their drawing ability (usually by expressing, "I'm not very good at drawing"), the student was informed that the interviewer wanted to learn about their ideas regarding geological concepts and was not concerned about artistic abilities. Students were encouraged to add any elements or characteristics they associated with the topic and to add notations to the drawing if they wished. Clarification was sought on any element students had drawn or written that was not understood by the researcher (Polkinghorne, 1989). Students were provided a pencil, with eraser, and a standard letter-sized sheet of white paper to complete their drawings.

The think-aloud interview protocol used to guide the discussion with each participant about his or her understanding of Earth's interior and their drawing progressed from general to specific, allowing for branching questions to facilitate verbal elaboration based on recommendations by Denzin and Lincoln (1998). With respect to Earth's interior, each student was asked a specific focus question: "If you could take a knife and cut Earth in half, 
what would it look like on the inside?" The researcher held an oval-shaped, 5 -cm plastic egg that was used to demonstrate splitting Earth in half (Beilfuss (McAllister), et al., 2003). However, only the first 35 students were shown the toy egg to demonstrate a cross-section of Earth; it was thought that the plastic egg might encourage students to consider Earth's interior like the inside of an egg, and this might unduly influence the students' thinking by inadvertently presenting them with an analogy, so the use of the egg was discontinued throughout the remaining interviews. Students were then asked to draw a picture that represented what the inside of Earth might look like. Probing questions were asked depending on the students' verbal and pictorial response. Once the student used specific terminology, such as "asthenosphere," the interviewer could probe the student's understanding further by asking the student to define these terms. The following is an example of the types of interview questions and probing questions that were asked of students:

Question: If you could take a giant knife and cut the Earth in half, what would you expect to see? Draw a picture that represents what the inside of the Earth might look like.

Probing question (after the student has drawn the core, mantle, crust): What is it like in the core? If we could take a trip there, what would it be like? (Depending on what the student says next): What makes the core hot?

Probing question: What else about the core do you know? How is it different/similar than the outer layers, inner layers that you've drawn there?

Probing question: You've drawn the magma/lava coming out of the volcano. Tell me more about your picture. Where does the magma/lava come from?

\section{RESULTS}

Questioning and drawing tasks in previous research suggested that the drawings, if executed well, could provide richer data than verbal descriptions alone. Overall patterns of student understanding were analyzed using qualitative analysis coding techniques (Patton, 1990). Patterns emerged that indicated a range of viewpoints, from a "simplistic representational" view - what Chi (1994) would call a "matter-based" view - to a more "causal/process oriented view" of Earth processes (Keil, 1995).

In prior research, drawings have been analyzed by using grouping techniques to categorize students into levels of understanding, or cognitive levels (Dove, 1999; Edens \& Potter, 2003; Paivio, 1990; Rennie \& Jarvis, 1995). Indexing, by counting and recording the features in students' drawings, has also been used as an analysis technique (Reiss, et al., 2002). This study utilized both indexing and grouping techniques to assess students' understanding of Earth's interior. The indexing process comprised counting and recording the features that were present within students' drawings. Features within the student-generated drawings, such as the presence of the core, mantle, and crust as concentric layers or flat layers, were recorded. Other features, such as the physical state of Earth's core, were also noted.

After reviewing the drawings and interviews, it was observed that the data naturally grouped into several categories. A series of levels of understanding was created by operationally defining each level (using the content of the drawings and interview transcriptions as a guide). After a review of 35 drawings and interviews using the operationally defined levels, it was determined that a more detailed description of each level of understanding was necessary in order to best represent the data (Beilfuss (McAllister), et al., 2003). Each level of understanding was reviewed by two science educators and revised to more accurately and completely define each level.

The levels of understanding identified for these drawings and interviews focused on students' views of Earth's interior and processes that occur on, or in, Earth. For example, levels of student understanding, exhibited by the interviews and drawings, progressed from simple, nonscientific views of the interior of Earth as consisting of horizontal layers of rock and dirt, to scientific conceptions in which the interior is composed of concentric layers with unique physical and chemical characteristics. Each drawing and interview was analyzed and then placed accordingly. It should be noted that none of the drawings were to scale, and this was primarily due to the limitations 
of this data collection technique; students were given limited time to sketch their conception of Earth's interior. Additionally, it is difficult to draw a "to-scale" model of Earth's interior with pencil and paper. And all drawings exhibited exaggerated thicknesses of internal layers within Earth. Thus scale was not considered in categorizing the drawings.

The criteria used to evaluate understanding included whether students had first identified key features within typical models of Earth's interior, such as the core, mantle, and crust. Many students included features found in scientific models of Earth's interior that are most commonly observed in Earth science texts. Although this practice should be discouraged, because each model has specific chemical and/or physical characteristics important to explaining other processes (such as plate movement), the significant number of students mixing the scientific models prohibited using this characteristic as a factor for discriminating among students' level of understanding. In order to be designated as being at a higher cognitive level, the student must have also correctly drawn and/or stated their understanding of physical or chemical changes that occur within Earth. Examples of this would be changes in temperature or density. The final level of understanding was reserved for those students who had achieved all the criteria of the previous levels, but had also demonstrated an understanding of processes, such as convection, that occur within Earth and summarized in Table 2.

Table 2: Levels of Student Understanding and Percent Occurrence Among Participants.

\begin{tabular}{|c|c|c|}
\hline Level of Understanding & Definition & $\%$ Students $(\mathrm{N}=91)$ \\
\hline [1] & $\begin{array}{l}\text { Key features of Earth's interior are absent or mislabeled. The } \\
\text { student gives no indication that there are physical or chemical } \\
\text { changes that occur within Earth. }\end{array}$ & $22 \%$ \\
\hline [2] & $\begin{array}{l}\text { Key features are present and labeled. The student discusses/labels } \\
\text { physical and/or chemical characteristics of Earth's interior. Some } \\
\text { alternative conceptions may be present at this level of } \\
\text { understanding. }\end{array}$ & $49 \%$ \\
\hline [3] & $\begin{array}{l}\text { Key features are present and labeled appropriately. Both the } \\
\text { student's drawing and interview exhibit a scientifically correct } \\
\text { conception of Earth's interior. However, at this level, the student } \\
\text { does not draw or discuss processes or causes of change within } \\
\text { Earth. }\end{array}$ & $20 \%$ \\
\hline [4] & $\begin{array}{l}\text { Key features are present and labeled appropriately. Both the } \\
\text { student's drawing and interview exhibit a scientifically correct } \\
\text { conception of Earth's interior. The student also discusses or } \\
\text { draws processes or causes of change within Earth (e.g., } \\
\text { temperature change, density change, or convection currents). For } \\
\text { example, within the drawing a student might indicate that a } \\
\text { process is occurring by using arrows to show plate movement or } \\
\text { movement of materials within Earth. }\end{array}$ & $9 \%$ \\
\hline
\end{tabular}


An example of a student's drawing illustrating each level of understanding is provided in Figure 1.
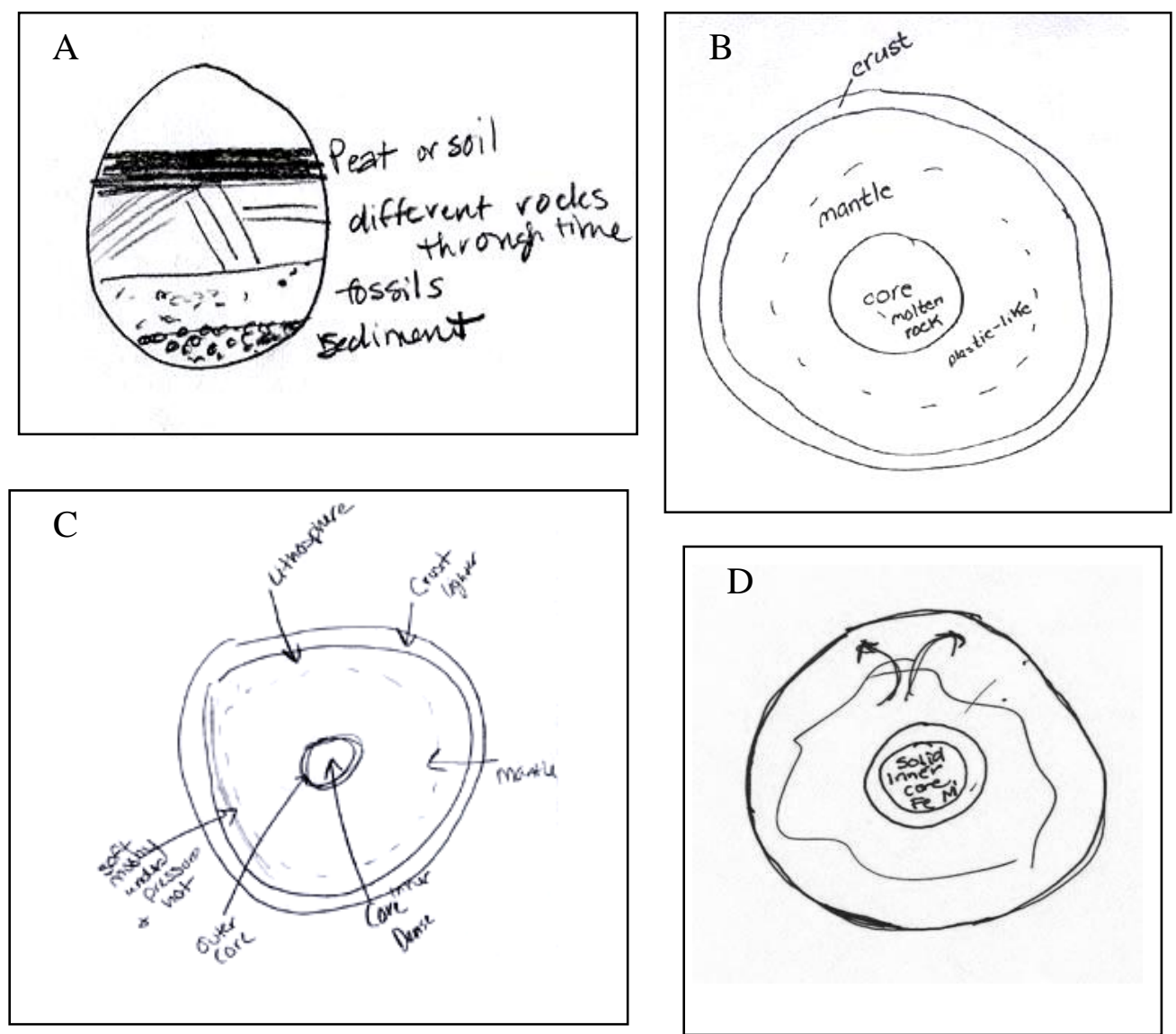

Figure 1: Student Drawings Representative Of The Four Levels Of Understanding In Table 2

Figure 1 shows samples of student drawings representative of the levels of understanding in Table 2. A typical example is A) Level One. Students sometimes constructed linear layers consisting of similar materials. In contrast, in B) Level Two, three concentric layers are drawn and labeled. In this case, the interviewee provided very little explanation of meaning of terms or reasons for layers. Notice that this student labeled the core as "molten rock." In C) Level Three, the student sketched concentric layers, which are labeled and explained. Elements of both chemical-composition and physical-state models have been mixed in this response. Finally, in the sample D) Level Four, the student's interview transcript and drawing indicated a relatively more accurate scientific explanation with differentiation of layers in Earth's interior drawing. Additionally, the movement of material within Earth, and in particular in relation to plate tectonics, is illustrated and revealed in the transcript as, "There's a solid core with mostly iron and nickel and metal. And then the outer core is liquid, like more liquid metals. And then the mantle is fluid or something with the asthenosphere where it is formed."

By operationally defining each level, and by analyzing both the interview and the drawing together, it was hoped to achieve a measure of content validity overall (Nelson, Aron, \& Francek, 1992). Construct validity is achieved by the consistency observed between a given student's interview and drawing. Use of the drawing task, in combination with the interview, allows for further examination, and confirmation, of students' mental processes.

To assess inter-rater reliability, the author and a collaborating colleague independently separated the first 35 interviews and drawings into levels of understanding. Initial ratings were highly consistent and had an initial inter-rater reliability of $97 \%$. Further discussion between researchers was initiated, with the opportunity to clarify researcher understanding of the levels based upon any significant differences in placement, until the placement was 
in $100 \%$ agreement. Since the inter-rater reliability was so high and the judgments seemingly straightforward, the remaining interviews were then assigned a level by the author only.

In addition to the drawing analysis, a scientific content analysis of interviews was conducted using thematic analysis advocated by White and Gunstone (1992). After a review of interview transcripts, two themes were inherent in the data: those that were considered a "static" conception and those considered to be "dynamic" views. These two emergent themes (Beilfuss (McAllister), et al., 2003; Beilfuss (McAllister), 2004) were clear from the interview transcripts. Specifically, if the student exhibited a conception of Earth's interior that included a discussion of changes in temperature, density (explicitly stated by the student and not assumed by the material the student had drawn), or the movement of materials within Earth, then the interview response was coded as "dynamic." Similarly, if the student exhibited a conception of Earth's interior that included no mention of changes in temperature, density, or movement of matter within Earth, then the interview response was coded as "static." A static conception of Earth's interior is itself an alternative conception, since Earth is a dynamic system.

Most Level One students drew a flat Earth with horizontal layers of rock, soil, water, and even "gravity." The vast majority of the 92 participating students $(97 \%, n=88)$ depicted key features, such as core, mantle, and crust, appropriately, albeit without explanations of terminology. However, these students still exhibited at least one alternative conception, such as that Earth's core is liquid, within their interview and/or drawing, placing these students at a Level Two. Those students who exhibited a scientifically correct conception of Earth's interior also generally expressed a more complex view of the concept by discussing features such as density changes or temperature changes within Earth. However, at this Level Three, the students left out a discussion or indication of processes or causes of change within Earth. Few students were able to accurately depict Earth's interior, and the majority of students did not talk about processes, such as convection, occurring within Earth. Those students who held a scientifically accurate conception of Earth's interior and discussed or indicated plate movement, convection, or causes of density or temperature changes within Earth were assigned a Level Four (9\%, n=8).

Individual drawings were examined to determine the features students associate with Earth's interior and are summarized in Table 3. The most commonly occurring features were concentric layers $(97 \%, \mathrm{n}=88)$ and physical-state and/or chemical-composition explanations $(92 \%, \mathrm{n}=82)$. Almost all drawings included labels for the core, mantle, and crust, with limited mislabeling. Interestingly, $38 \%$ of students described the inner core as a liquid, instead of a solid. Few $(22 \%, \mathrm{n}=20)$ students included the differentiation of the lithosphere and asthenosphere within Earth. Indeed, most students tended to mix scientific models within their drawings. For example, the mantle was labeled as "mushy" or "partially solid," or the composition of the inner core was described as iron, with no indication of the chemical composition of any other layers.

Table 3: Observed Characteristics Of Drawings Of Earth's Interior $(\mathrm{N}=90)$

\begin{tabular}{lc}
\hline \multicolumn{1}{c}{ Student Responses } & \% of Drawings \\
\hline Earth's interior as concentric layers & $97 \%$ \\
Earth's interior as concentric layers with physical and/or chemical features noted & $92 \%$ \\
Earth's interior as nonconcentric layers & $3 \%$ \\
Soil and rock composition only & $3 \%$ \\
Liquid inner core & $38 \%$ \\
Solid inner core & $62 \%$ \\
\hline
\end{tabular}

Student discussions of the underlying processes related to the interior of Earth were quite limited. Sixtythree percent $(n=57)$ of students failed to discuss processes such as convection or plate tectonics, even when probed. Some recognized individual features (such as "core," "mantle," and "crust"), but they often failed to explain the relationship of these elements to each other in the overall system. Some elements (such as "plates" and "magma") were frequently mentioned, but were poorly understood. Furthermore, when students were asked several elaboration questions by the interviewer, generally student responses provided little additional insight into students' conceptions. 


\section{DISCUSSION}

Overall, students possessed a number of alternative conceptions about Earth's interior, and these conceptions affected the visual models depicted in student drawings. Although most students explained Earth's interior as a set of concentric circles and provided technical labels for each layer, few were able to accurately or completely explain their reasons for this subdivision. Predominant explanations generally mixed chemicalcomposition and physical-state rationales, indicating that most students, even those with complex understanding of internal processes, were unable to differentiate the two scientific models for Earth's interior - each describing phenomena based upon both physical and chemical characteristics. While most students indicated that dynamic movement or changes, either of physical state or density, occur within Earth, a few students viewed Earth as a static body made up of a single or related materials, such as dirt, soil, water, or rock.

Wide-ranging conceptions and descriptions of Earth's interior exist among the study population. The fact that most students exhibited a partial understanding of Earth's interior suggests that the relationships among unique features and processes, such as the mantle and convection, should be explored further within the college classroom. The findings also suggest that while students are generally familiar with scientific terms from the chemicalcomposition and physical-state models of Earth's interior, students' understanding of these properties was limited. Simple use of technical terms, without the ability to explain underlying concepts, likely hinders learning (Medin, 1998). Understanding the nature of the evidence behind the construction of models of Earth's interior would likely allow for a better undergraduate student understanding of the structure and dynamic nature of Earth's interior and related phenomena.

The majority of students understood that Earth has concentric layers, but did not understand completely the chemical and physical characteristics of each layer. Similar to King's (2000) observations of the alternative conceptions held by in-service teachers, $38 \%$ of undergraduates studied here believed that the inner core is a liquid. When probed to explain why they believed the inner core was liquid, students often explained that the core had to be a liquid since they knew it was also very hot.

When students described their drawings or answered interview questions, they used terminology, such as lithosphere, without a complete understanding of what that concept means. When probed, most students could not define terms such as "lithosphere" or "asthenosphere," even though they had themselves used these terms were used to describe the layers within Earth. However, an understanding of the physical-state model of Earth's interior, as well as its relationship to the chemical-composition model, is an important prerequisite to understanding plate motion. The boundary between the mantle and the crust is defined by chemical differences between them; the crust is made up largely of less dense, silica-rich rocks, whereas the mantle comprises more dense, silica-poor and ironrich rocks. The lithosphere, which comprises both the crust and upper mantle, is broken up into the tectonic plates. The asthenosphere, beneath the lithosphere, is near its melting point and contains enough liquid to allow it to behave in a ductile manner, allowing for plate tectonic motion. In both interviews and drawings, students often referred to this layer as a magma layer, or simply confused the mantle and the asthenosphere as the same thing. Similarly, King (2000) found that students placed a "mushy" or "partially melted magma" layer beneath Earth's surface, confusing magma with asthenosphere.

Many students in this study did not understand the processes, such as convection, occurring in Earth's interior or the results of those processes, such as plate movement. Students' lack of understanding of Earth's processes indicates that they do not have a complete understanding of the causes of plate tectonics and other naturally occurring phenomena, such as earthquakes and volcanoes. Furthermore, the presence of a "static" conception of Earth's interior should be noted by geoscience instructors, so that when the topic of plate tectonics is introduced, a review of Earth's interior should follow. Certainly, those students without a clear understanding that Earth is modeled by scientists as a series of concentric layers with different properties will have a difficult time understanding related concepts, such as plate tectonics. While students did not specifically point to textbooks as a source of confusion, the lack of explanatory text in textbook illustrations may be partially to blame for the prevalence of alternative conceptions. Textbooks often present images by simply labeling the key features without adding any explanatory text that would encourage the development of a process understanding among students. For 
instance, Mayer (1993) observed that science textbooks allocate 50\% of textbook space to illustrations, with less than $10 \%$ of the illustrations presenting an image in an explanatory manner.

Finally, similar to Lillo's (1994) study, most students in this study drew a two-dimensional image of Earth's interior, with three or four concentric layers typically labeled core, mantle, and crust. The defining features of most concepts are complex and hard to specify. Category boundaries are not always clear-cut, so individuals tend to view concepts holistically, in terms of 'best examples' or 'prototypes', especially when the concepts have fuzzy boundaries (Martorella, 1991). Clearly these findings suggest that students in introductory geoscience courses have been exposed to geoscience concepts prior to undergraduate coursework, arrive at Earth science college classrooms at all levels of conceptual understanding, and are most likely exhibiting a prototypical view of the concept.

In this study, students' understanding ranged from a nonscientific conception of Earth's interior at one end of the spectrum, and at the other end an understanding that was not only scientifically correct, but also included a conceptual understanding of processes occurring in Earth's interior. Results from this study provide a basis from which to further our understanding of student thinking, and contribute to the body of knowledge and research on Earth science alternative conceptions and conceptual development. These findings are also important for studies of conceptual change, since the determination of conceptions of natural phenomena that students can be expected to bring to the classroom will in turn provide insight into how well students are learning science (Heller \& Finley, 1992).

\section{IMPLICATIONS}

Keeping this in mind, undergraduate instruction about Earth's interior may be best focused on the interconnecting processes involved in Earth's interior, rather than on instruction that focuses on learning of terminology. Instruction that does not provide an opportunity for students to become dissatisfied with their current conceptions, or that does not acknowledge the existence of preexisting ideas, may not be capable of prompting students to successfully modify their conception to achieve a more complete and/or scientifically correct understanding.

While classroom instruction about Earth's interior occurs early in students' lives, with $62 \%$ of these undergraduates having taken an Earth science course in middle school or high school, the interviews and drawings very frequently indicated incomplete student understanding. This incomplete understanding is likely a result of the abstract nature of the concepts under study. The mechanisms causing a geological process, such as plate tectonics, or the evidence for models of Earth's interior, cannot be observed directly, and are therefore considered an instructional challenge for science educators.

These results encourage recommendations to Earth science instructors summarized as these directives:

1. Assess students' prior knowledge before beginning instruction.

2. Use student-generated drawings to promote understanding of abstract concepts.

3. Use a series of student-generated drawings to promote conceptual change if alternative conceptions are present.

4. Promote the use of explanatory text with textbook diagrams, and draw attention to the explanatory text during instruction.

5. Promote the instruction of this and other abstract concepts using analogies, metaphors, the construction of physical models, and similar techniques.

This study's results further encourage recommendations that educators in the K-12 grades ensure that students are developmentally ready to understand such abstract concepts prior to instruction, mainly by providing further instruction on those prerequisite concepts, such as density and convection, that are important to the formation of a complete understanding of Earth's interior. It is further recommended that K-12 instruction about Earth's interior and similar abstract concepts should utilize drawing as an instructional delivery and assessment tool. The use of drawing in introductory college geology survey courses might also lead to the subsequent development of better pedagogical practices that promote conceptual change. 


\section{ACKNOWLEDGEMENTS}

This dissertation study was supported by a National Science Foundation Assessment of Student Achievement in Undergraduate Education grant (Libarkin \& Anderson: DUE-0127765). I would like to thank William Boone and Julie Libarkin for their contributions to this research study.

\section{AUTHOR INFORMAITON}

Dr. Meredith L. McAllister is an Associate Professor of Education at Butler University where she teaches courses for future teachers in geosciences education. Specializing in discipline-based education research in the geosciences, this article describes a portion of her Ph.D. dissertation work in science education from Indiana University. E-mail: mlcalli@butler.edu

\section{REFERENCES}

Abimbola, I. O. (1988). The problem of terminology in the study of student conceptions in science. Science Education, 72(2), 175-184.

Ault, C. (1984). The everyday perspective and exceedingly unobvious meaning. Journal of Geological Education, 32(2), 89-91.

Bar, V. (1989). Children's views about the water cycle. Science Education, 73(4), 481-500.

Beilfuss (McAllister), M., Libarkin, J., \& Boone, W. (2003). College students' views of the Earth's interior: Implications for science educators. Unpublished white paper.

Beilfuss (McAllister), M. (2004). A study of undergraduate students' alternative conceptions of the Earth's interior using drawing tasks. Ph.D. Dissertation, Indiana University. Proquest ISBN: 9780496886685, Dissertation Abstracts International, Volume: 65-07, Section: A, page: 2545.

Bezzi, A., \& Happs, J. (1994). Belief systems as barriers to learning in geological education. Journal of Geological Education, 42(2), 134-140.

Brown, D. (1989). Students' concepts of forces: The importance of understanding Newton's third law. Physics Education, 24(11), 353-357.

Chang, C., \& Barufaldi, J. (1999). The use of a problem-solving based instructional model in initiating change in students' achievement and alternative frameworks. International Journal of Science Education, 21(4), 373388.

Chi, M., Slotta, J., \& Leeuw, N. (1994). From things to processes: A theory of conceptual change for learning science concepts. Learning and Instruction, 4(1), 27-43.

Clement, J., Brown, D. E., \& Zietsman, A. (1989). Not all preconceptions are misconceptions: finding 'anchoring conceptions' for grounding instruction on students' intuitions. International Journal Of Science Education, 11(5), 554-565.

Cornett, C. (2002). Creating meaning through literature and the arts (2nd ed.). Upper Saddle River, NJ: Merrill Prentice Hall.

Dal, B. (2007). How do we help students build beliefs that allow them to avoid critical learning barriers and develop a deep understanding of geology. Eurasia Journal of Mathematics, Science \& Technology Education, 3(4), 251-269.

DeLaughter, J. E., Stein, S., Stein, C. A., \& Bain, K. R. (1998). Preconceptions abound among students in an introductory earth science course. Eos, Transactions American Geophysical Union, 79(36), 429-432.

Denzin, N. K., \& Lincoln, Y. S. (Eds.). (1998). Strategies of qualitative inquiry. Thousand Oaks, CA, Sage Publications, 346.

diSessa, A., \& Sherin, B. (1998). What changes in conceptual change? International Journal of Science Education, 20(10), 1155-1191.

Dove, J. (1998). Students' alternative conceptions in Earth science. Research Papers in Education, 13(2), 183-201.

Dove, J. (1999). Exploring a hydrological concept through children's drawings. International Journal of Science Education, 21(5), 485-497.

Driver, R. (1989). Students' conceptions and the learning of science. International Journal of Science Education, $11(5), 481-490$. 
Edens, K., \& Potter, E. (2003). Using descriptive drawings as a conceptual change strategy in elementary science. School Science and Mathematics, 103(3), 135-144.

Gabel, D. (1989, September). Let us go back to nature study. Journal of Chemical Education, 66(9), 727-29.

Gobert, J., \& Clement, J. (1998). Effects of student-generated diagrams versus student-generated summaries on conceptual understanding of causal and dynamic knowledge in plate tectonics. Journal of Research in Science Teaching 36, 39-53.

Hall-Wallace, M. (2002, October). Visualizing Earth's inaccessible interior: What works for students? Proceedings of the Geological Society of America Annual Meeting, Denver, CO.

Heller, P., \& Finley, F. (1992). Variable uses of alternative conceptions: A case study in current electricity. Journal of Research in Science Training, 29(3), 259-275.

Keil, F. C. (1995). The growth of causal understandings of natural kinds. In Sperber, S., Premack, D., \& Premack, A. (Eds.), Causal cognition: A multi-disciplinary debate. Cambridge: Oxford University Press, 234-262.

King, C. (2000). The Earth's mantle is solid: Teachers' misconceptions about the Earth and plate tectonics. School Science Review, 82(298), 57-65.

Libarkin, J. C., Beilfuss (McAllister), M., \& Kurdziel, J. (2003). Research methodologies in science education: Mental models and cognition in education. Journal of Geoscience Education, 51(1), 121-126.

Libarkin, J. C., Anderson, S., Dahl, J., Beilfuss (McAllister), M., Boone, W., \& Kurdziel, J. (2003b). Qualitative analysis of college students' ideas about Earth: interviews and open-ended questionnaires. Journal of Geoscience Education, 53(1), 17-26.

Lillo, J. (1994). An analysis of the annotated drawings of the internal structure of the Earth made by students aged 10-15 from primary and secondary schools in Spain. Teaching Earth Sciences, 19(3), 83-89.

Martorella, P. (1991). Knowledge and concept development in social studies. In Shaver, J. (Ed.), Handbook of Research on Social Studies Teaching and Learning. New York: Macmillan International.

Marques, L., \& Thompson, D. (1997a). Misconceptions and conceptual changes concerning continental drift and plate tectonics among Portuguese students aged 16-17. Research in Science and Technological Education, 15(2), 195.

Mayer, R. (1993). Illustrations that instruct. In Glaser, R. (Ed.), Advances in instructional psychology. Hillsdale, NJ: Erlbaum, 4, 253-284.

Medin, D. (1998). Concepts and conceptual structure. American Psychologist, 44(12), 1469-1481.

Muthukrishna, N., \& Carnine, D. (1993). Children's alternative frameworks: Should they be directly addressed in science instruction? Journal of Research in Science Teaching, 30(3), 233-248.

Nelson, B., Aron, R., \& Francek, M. (1992). Clarification of selected misconceptions in physical geography. Journal of Geography, 91(1), 76-80.

Nottis, K., \& Ketter, K. (1999). Using analogies to teach plate tectonics concepts. Journal of Geoscience Education, 47(5), 449-54.

Paivio, A. (1990). Mental representations: A dual-coding approach (2nd ed.). New York: Oxford University Press.

Palmer, D. (1999). Exploring the link between students' scientific and nonscientific conceptions. Science Education, 83(6), 639-653.

Patton, M. Q. (1990). Qualitative Evaluation and Research Methods (2nd ed.). Newbury Park, CA: Sage Publications, 532.

Polkinghorne, D. (1989). Phenomenological research methods. In Valle, R. S. \& Halling, S. (Eds.), Existentialphenomenological perspectives in psychology. New York: Plenum, 41-60.

Reiss, M., Tunnicliffe, S., Andersen, A., Bartoszeck, A., Carvalho, G., Chen, S., Jarman, R., Jonsson, S., Manokore, V., Marchenko, N., Mulemwa, J., Novikova, T., Otuka, J., Teppa, S., \& Rooy, W. (2002). An international study of young peoples' drawings of what is inside themselves. Journal of Biological Education, 36(2), 5864.

Rennie, L. J., \& Jarvis, T. (1995). Children's choice of drawing to communicate their ideas about technology. Research in Science Education, 25(3), 239-252.

Samarapungavan, A., Vosniadou, S., \& Brewer, W. (1996). Mental models of the Earth, sun, and moon: Indian children's cosmologies. Cognitive Development, 11, 491-521.

Schoon, K. (1989). Misconceptions in the Earth Sciences: A Cross-Age Study. National Association for Research in Science Teaching Conference Proceedings. San Francisco, CA: ERIC: http://files.eric.ed.gov/fulltext/ED306076.pdf 
Sharp, J. G., Mackintoch, M. A. P., \& Seedhouse, P. (1995). Some comments on children's ideas about Earth structure, volcanoes, earthquakes, and plates. Teaching Earth Science, 20(1), 28-30.

Skinner, B., Botkin, D., \& Porter, S. (1995). The blue planet: An introduction to Earth system science. Canada: John Wiley \& Sons.

Solomon, J. (1987). Social influences on the construction of pupils' understanding of science. Studies in Science Education, 14(1), 63-82.

Stead, B., \& Osborne, R. (1980). Exploring science students' concepts of light. The Australian Science Teachers Journal, 26(3), 84-90.

Vosniadou, S., \& Brewer, W. F. (1992). Mental models of the Earth: A study of conceptual change in childhood. Cognitive Psychology, 24, 535-585.

Wandersee, J. H., Mintzes, J. J., \& Novak, J. D. (1994). Research on alternative conceptions in science. Handbook of Research on Science Teaching and Learning. New York: Macmillan, 177-210.

White, R., \& Gunstone, R. (1992). Probing Understanding. London: Falmer Press. 


\section{NOTES}

